Sharif University of Technology
Scientia Iranica
SCIENTIA
I RAN I CA

\title{
Fuzzy supervisory control of a seismic shake table
}

\author{
M. Hamidizadeh ${ }^{\mathrm{a}}$, M. Soleymani ${ }^{\mathrm{a}, *}, \mathrm{H}$. Moradzadeh $^{\mathrm{b}}$ and B. Ghanbari-S \\ a. Department of Mechanical Engineering, Faculty of Engineering, Arak University, Arak, P.O. Box 38156-8-8349, Iran. \\ b. Department of Electrical Engineering, Faculty of Engineering, Arak University, Arak, P.O. Box 38156-8-8349, Iran. \\ Received 26 April 2014; received in revised form 8 August 2015; accepted 19 September 2015
}

\author{
KEYWORDS \\ Seismic shake table; \\ Electric; \\ Motion control; \\ Tracking; \\ Fuzzy supervisory.
}

\begin{abstract}
This work addresses the design and implementation of a novel fuzzy supervisory control approach for the motion control of a seismic shake table. For this purpose, a single degree of freedom laboratory-scale electric shake table was developed. The control scheme comprises two loops: a PI inner loop and a fuzzy outer loop as the supervisor. Three separate supervisory controllers are proposed and implemented in the shake table, and their performance in tracking two real earthquakes is assessed via extensive shake table testing. The test results reveal the effectiveness of the fuzzy supervisory controller in reducing displacement and acceleration tracking errors.
\end{abstract}

(C) 2016 Sharif University of Technology. All rights reserved.

\section{Introduction}

Earthquakes are natural disaster events that can cause damage and injury if structures are not sufficiently fortified to withstand them. In order to study the structural response variables of civil structures and evaluate their robustness against seismic loads, shake table tests may be employed. An earthquake shake table is a device that simulates strong ground motions. Depending on its size and payload, it can be employed to test full or laboratory-scale civil structures. Shake tables have been extensively used for structural dynamics testing in recent years [1-4].

Aside from their size and degrees of freedom, shake tables are classified as electric or hydraulic types. Hydraulic shake tables utilize hydraulic power and can produce huge forces. These are suitable for testing large structures. Electric shake tables, on the other hand, employ an electric motor as a deriving system and are usually designated for testing light structures.

\footnotetext{
* Corresponding author. Tel: +98 86 32622722;

Fax: +988632625723

E-mail addresses: m-hamidizadeh@arshad.araku.ac.ir (M. Hamidizadeh); m-soleymani@araku.ac.ir (M. Soleymani); h-moradzadeh@araku.ac.ir (H.Moradzadeh); ghanbaribahador@gmail.com (B. Ghanbari-S)
}

Since 1890 , when the first laboratory shake table was built by Milne and Omori in Japan, several shake tables have been developed [5-8].

The main core of a shake table is its control system, whose principal function is to control the shake table motions based on feedback error signals in order to emulate the dynamic characteristics of an earthquake. In this study, the effectiveness of a shake table control system is evaluated by measuring the tracking error, i.e. the deviation in simulated motion achieved by the shake table from the reference motion acquired from a real or synthetic earthquake profile.

Tracking control of a seismic shake table is normally performed via a feedback control system, in which the reference and response signals are compared continuously and the control command is calculated based on the error signals. Several control approaches have been employed for this purpose. For example, Azalée [9], a six-degree of freedom shake table, utilizes a control strategy with three loops. Seki et al. [10] proposed an adaptive feedback compensator for a shake table and mounted structure control. Yang et al. [11] improved the tracking characteristics of a laboratory shake table using a three-state feedback and feedforward control algorithm based on the pole assignment principle. Time Delay Control (TDC) 
was used to improve the tracking performance of a shake table by Lee et al. [12]. Chase et al. [13] developed a controller to reduce acceleration spikes. Ji et al. [14] considered controlling an array of nine sub-tables with sixteen servo actuators. Airouche et al. [15] studied the application of a variety of controllers ranging from Amplitude Phase Control (APC) and Adaptive Harmonic Cancellation (AHC) to Adaptive Inverse Control (AIC) and online iteration (OLI) for shake table control. DE Canio et al. [16] considered applying 3-dimensional image processing to 3 variable controls on a hydraulic shake table.

Fuzzy Logic Control (FLC) as an effective control approach has attracted considerable interest in current years and has several advantages. First, it is possible to integrate the knowledge of an expert into the design procedure in terms of verbal statements. Besides, it does not require an exact model to function. This is a key advantage in the control of systems like shake tables, where the exact system model is not available. Finally, FLC is inherently robust and has great potential for adaptability, which makes it a good choice for controlling systems with uncertainties [17]. In order to enhance control performance, FLC may be combined with another control approach in a hierarchical control strategy. In this scenario, the system is controlled through a two-loop control system, where the inner loop is usually faster and sends control output directly to the system and the outer loop acts as a supervisor to improve the inner loop performance [18]. The fuzzy supervisory control approach has been successfully employed to control a base isolated benchmark building [19]. However, no work has addressed shake table motion control tables using this control approach. Application of fuzzy-supervisory controller to control seismic shake tables may be beneficial according to the following reasons:

1. Most of controllers provided by the motor-drive builders are of conventional PID type. In this case, performance of the controller is not optimal for all simulated earthquakes. Supervisory control can be added to these controllers as a modular outer loop to enhance tracking performance;

2. The designer knowledge can be simply translated to verbose statement for supervising purpose;

3. Fuzzy controller has an inherent robustness. It is very important that the shake table controller be robust in order to tackle systems uncertainties;

4. Fuzzy controller as the supervisor has a high potential of tunability, which makes it a good match for further optimizations.

The present study reports the application of a fuzzy supervisory control approach to control a laboratory-scale electric shake table. For this purpose, a single degree of freedom electric shake table is developed. The motion of the table is meant to be controlled primarily by a PI controller. A novel fuzzy logic controller is then designed and implemented in the shake table as the supervisor controller. The performance of the control system with and without a supervisor controller is subsequently evaluated via shake table tests.

This paper is structured as follows. The shake table configuration is initially introduced. The control design and implementation of the controller in the shake table is then described. Finally, the test results are presented and the control approach performance is discussed.

\section{Shake table configuration}

The developed shake table, LARZA, is depicted in Figure 1. LARZA is an electro-mechanical single degree of freedom seismic shake table that can simulate the horizontal motion of mild earthquakes of up to $100 \mathrm{~mm} / \mathrm{s}$ velocity and $2 \mathrm{~g}$ acceleration. It utilizes a $1 \mathrm{~kW}$ permanent magnet synchronous AC servo motor in conjunction with a ball-screw mechanism as the drivetrain system. Moreover, the rotational motion of

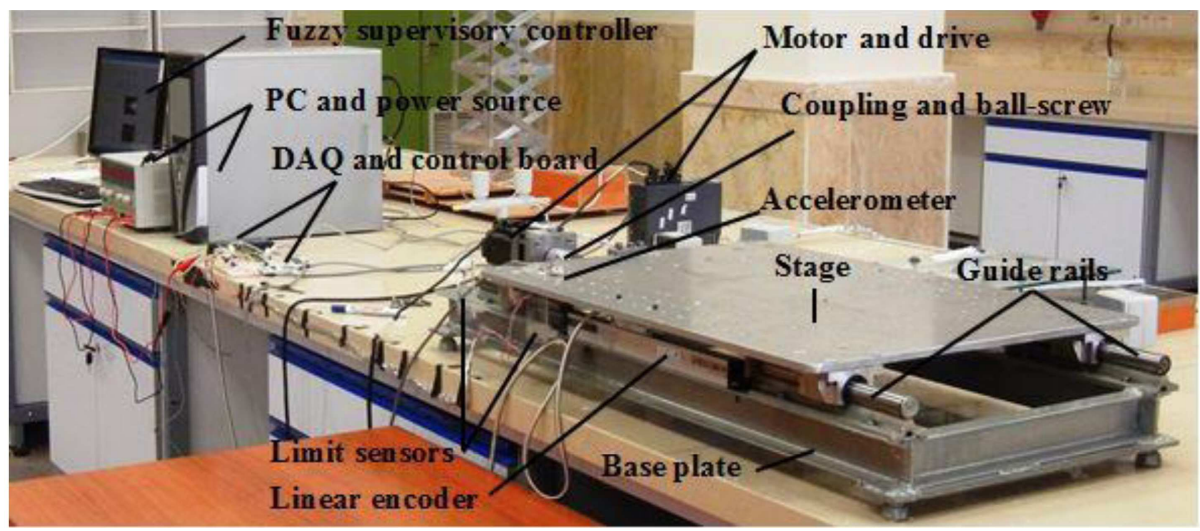

Figure 1. LARZA shake table. 
Table 1. Specification of LARZA.

\begin{tabular}{ll}
\hline \multicolumn{1}{c}{ Component/characteristics } & \multicolumn{1}{c}{ Value/description } \\
\hline Motor type & AC permanent magnet synchronous motor \\
Motor power & $1 \mathrm{~kW}$ \\
Table dimensions $(B \times L)$ & $750 \times 550 \mathrm{~mm}$ \\
Displacement $(\mathrm{mm})$ & \pm 90 \\
Maximum velocity $(\mathrm{mm} / \mathrm{s})$ & 1000 \\
Maximum acceleration $(\mathrm{g})$ & 2 \\
Maximum payload $(\mathrm{kg})$ & 35 \\
Ball-screw lead $(\mathrm{mm})$ & 20 \\
Acceleration sensor & dual-axis MEMS accelerometer with a measurement range of $\pm 1.7 \mathrm{~g}$ \\
Displacement sensor sensitivity $(\mu \mathrm{m})$ & 5 \\
\hline
\end{tabular}

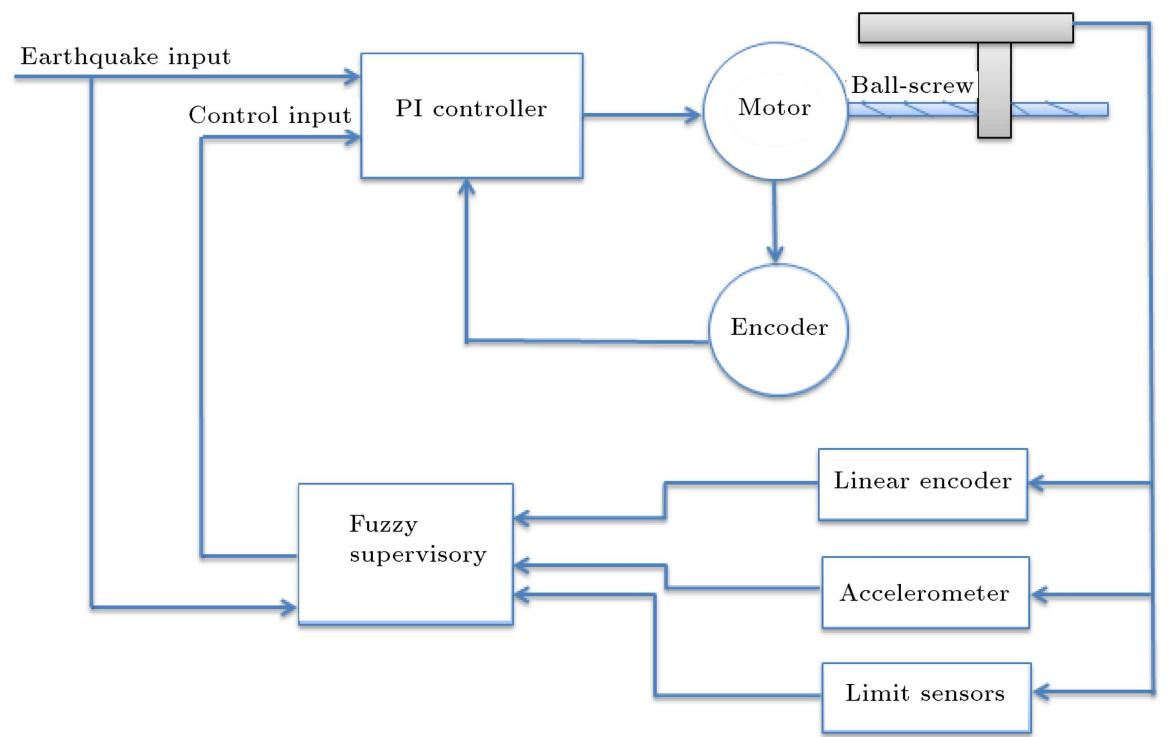

Figure 2. Schematic diagram of the control system.

the motor is translated into linear motion via a ballscrew mechanism. The table stage is $750 \times 550 \mathrm{~mm}$ with stroke of $\pm 80 \mathrm{~mm}$.

The sensor system includes a $5 \mu \mathrm{m}$ linear encoder that measures the stage displacement, a shaft encoder that measures the rotation angle of the electric motor shaft with 2500 pulses per revolution sampling frequency and an ADXL203 analog accelerometer that senses the horizontal acceleration of the stage. Moreover, the controller hardware includes a servo drive, a $200 \mathrm{kS} / \mathrm{s}$ 16-bit data acquisition (DAQ) card, an AT Mega 32 microcontroller, and a dual core Personal Computer (PC). Communication between these components takes place as follows. The linear encoder sends the acquired data to the microcontroller, which then calculates the shake table position and sends the information to the DAQ card as a 16-bit word. Meanwhile, acceleration data is acquired by the DAQ card, which is connected to the PC where the control program is implemented in Lab VIEW software. For safety reasons, two infrared CNY70 limit switches are used to shut down the system in case the stage travel exceeds the predefined stroke range of $\pm 90 \mathrm{~mm}$. Table 1.

The specifications of LARZA are summarized in

\section{Controller design and implementation}

The control scheme shown in Figure 2 comprises two loops, including an inner PI loop as the core controller and a fuzzy controller as the supervisor. In this scenario, the PI controller in the inner loop is the main component in the table's motion control, and it controls the motor speed based on the feedback error signals. The outer loop, i.e. fuzzy supervisory controller modifies the inner loop's performance. Basically, in this application, the supervisor controller is meant to enhance the tracking performance of the PI controller by compensating for the tracking errors. In 
Table 2. Fuzzy rule base for $\mathrm{FLC}_{1}$.

\begin{tabular}{cccccccc}
\hline Err. $_{\text {displacement }}^{\text {Err }_{\text {displacement }}}$ & PB & PM & PS & $\mathbf{Z}$ & NS & NM & NB \\
\cline { 1 - 6 } NB & PM & PM & PB & PB & PB & PB & PB \\
NM & PSS & PS & PS & PM & PM & PM & PB \\
NS & PSS & PSS & PS & PS & PS & PS & PS \\
Z & NSS & NSS & Z & Z & Z & PSS & PSS \\
PS & NS & NS & NS & NS & NS & NSS & NSS \\
PM & NB & NS & NM & NM & NS & NS & NS \\
PB & NB & NB & NB & NB & NB & NM & NM \\
\end{tabular}

this case, perfect tracking is achieved when the desired displacement, velocity, and acceleration adopted from a real or synthetic earthquake profile coincide with the corresponding values achieved by the shake table.

The reference signal for motor speed control is calculated by transforming the desired stage velocity to the required motor shaft speed using Eq. (1):

$$
\omega=\frac{v}{L}
$$

where $\omega$ is the electric motor rotational speed (reference signal), $v$ is the desired stage velocity corresponding to the earthquake horizontal velocity, and $L$ is the lead screw.

Three separate fuzzy supervisory controllers are proposed using various feedback error signals. In the first FLC, i.e. $\mathrm{FLC}_{1}$, displacement error and velocity error are considered error signals fed to the FLC. In the second FLC, i.e. $\mathrm{FLC}_{2}$, displacement error and acceleration error form the FLC inputs and finally, in the third, $\mathrm{FLC}_{3}$, velocity error and acceleration error are selected as the FLC control inputs. In all mentioned FLCs, the control command is the input voltage to the electric motor. Table 2 depicts the fuzzy rules developed for $\mathrm{FLC}_{1}$.

In this table, Err $_{\text {displacement }}$ is the displacement error and Err displacement $_{\text {is }}$ the displacement error rate (velocity error); NB, NM, NS, NSS, Z, PSS, PS, $\mathrm{PM}$, and $\mathrm{PB}$ represent negative big, negative medium, negative small, very negative small, zero, very positive small, positive small, positive medium, and positive big, respectively. Consider a rule, for instance, a rule for which both displacement and velocity errors are 'negative big' implying a large error and a strong tendency toward a larger error. In this case, a big reverse control command like $\mathrm{PB}$ would be required to counteract this large error. The other rules are written in the same manner. Furthermore, according to Figure 3, each input is described by seven membership functions. Similarly, the FLC output is described by nine membership functions, as shown in Figure 4.

The fuzzy rule bases for $\mathrm{FLC}_{2}$ and $\mathrm{FLC}_{3}$ are shown in Tables 3 and 4 , respectively.

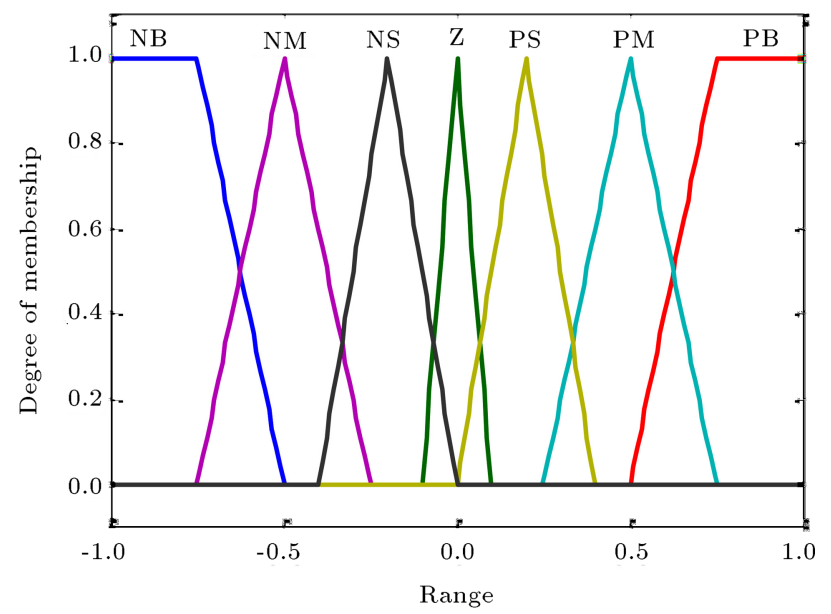

Figure 3. Input membership functions.

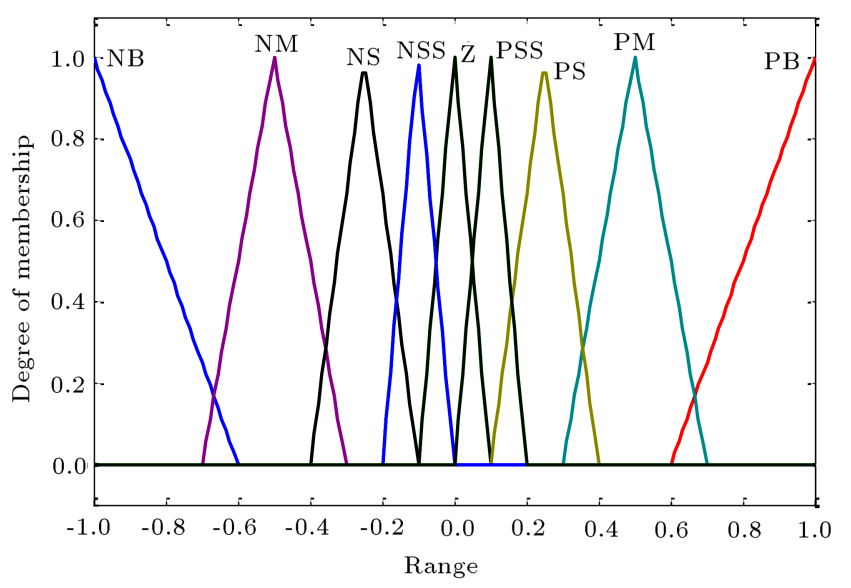

Figure 4. Output membership functions.

Table 3. Fuzzy rule base for $\mathrm{FLC}_{2}$.

\begin{tabular}{|c|c|c|c|c|c|c|c|}
\hline $\begin{array}{l}\text { Err }_{\text {acceleration }} \\
\text { Err }_{\text {displacement }}\end{array}$ & NB & NM & NS & $\mathrm{Z}$ & PS & PM & PB \\
\hline NB & $\mathrm{PB}$ & $\mathrm{PM}$ & $\mathrm{PM}$ & $\mathrm{PM}$ & PS & PS & PSS \\
\hline NM & $\mathrm{PM}$ & PM & $\mathrm{PM}$ & PS & PS & PSS & PSS \\
\hline NS & PS & PS & PS & PSS & PSS & $\mathrm{Z}$ & $\mathrm{Z}$ \\
\hline $\mathbf{Z}$ & PSS & Z & Z & Z & Z & Z & NSS \\
\hline PS & NSS & NSS & NS & NS & NS & NS & NS \\
\hline PM & NS & NS & $\mathrm{NM}$ & $\mathrm{NM}$ & $\mathrm{NM}$ & NM & NB \\
\hline PB & NM & NM & NB & NB & NB & NB & NB \\
\hline
\end{tabular}

\section{Test results and analysis}

The shake table test results are presented and discussed in this section. Four controls including a PI controller without a supervisor and the aforementioned fuzzy supervisory controllers were implemented in the shake table. Subsequently, the controllers' performance in tracking earthquake profiles was compared. A scaled version of the Kobe and Chalfant earthquakes [20] 
Table 4. Fuzzy rule base for $\mathrm{FLC}_{3}$.

\begin{tabular}{|c|c|c|c|c|c|c|c|}
\hline $\begin{array}{c}\text { Err }_{\text {velocity }} \\
\text { Err }_{\text {acceleration }}\end{array}$ & NB & NM & NS & $\mathbf{Z}$ & PS & $\mathbf{P M}$ & PB \\
\hline NB & PB & PB & PS & PSS & Z & NS & NS \\
\hline NM & $\mathrm{PB}$ & PB & PS & PSS & $\mathrm{Z}$ & NS & NS \\
\hline NS & $\mathrm{PB}$ & PM & PS & PSS & NS & NS & $\mathrm{NM}$ \\
\hline $\mathbf{Z}$ & PM & PM & PSS & $\mathrm{Z}$ & NSS & NS & $\mathrm{NM}$ \\
\hline PS & PM & PM & PSS & Z & NS & NM & NM \\
\hline PM & $\mathrm{PM}$ & PS & PS & NSS & NS & NM & NB \\
\hline PB & PS & PS & Z & NSS & NS & NB & NB \\
\hline
\end{tabular}

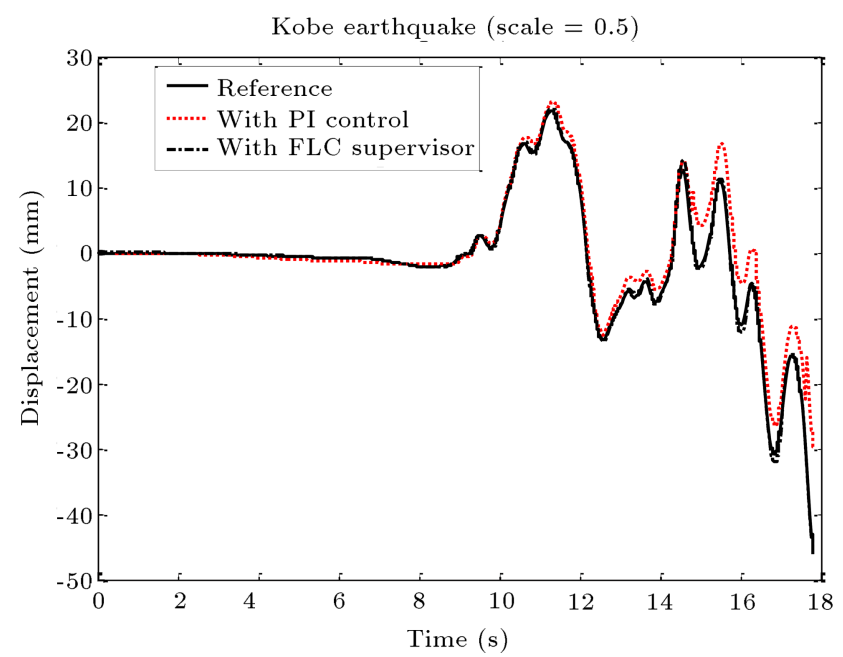

Figure 5. Stage displacement response with $\mathrm{FLC}_{1}$.

was employed for this purpose. Specifications of the mentioned earthquakes are given in Table 5 .

Figure 5 compares the displacement response histories for the shake table with PI and $\mathrm{FLC}_{1}$ controllers. As seen in this figure, employing a PI controller with no supervisor results in considerable tracking error, whereas applying the fuzzy supervisory controller in conjunction with the PI controller causes a drastic drop in tracking error.

Figures 6 and 7, respectively, depict the tracking performance of the $\mathrm{FLC}_{2}$ and $\mathrm{FLC}_{3}$ supervisory controllers, respectively. These figures indicate that $\mathrm{FLC}_{3}$ performs much better than $\mathrm{FLC}_{2}$. Nevertheless, $\mathrm{FLC}_{3}$ performs more poorly than $\mathrm{FLC}_{1}$, implying the superior performance of $\mathrm{FLC}_{1}$ in displacement tracking.

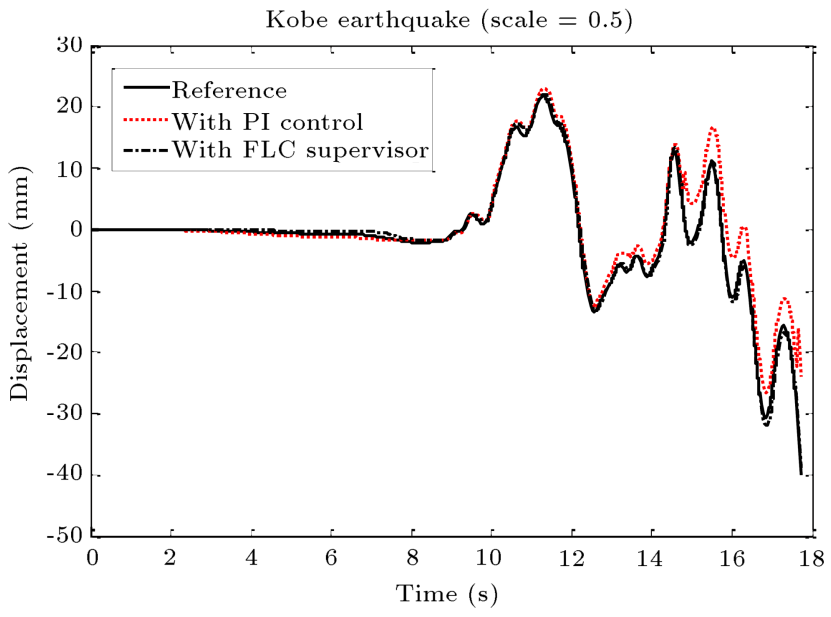

Figure 6. Stage displacement response with $\mathrm{FLC}_{2}$.

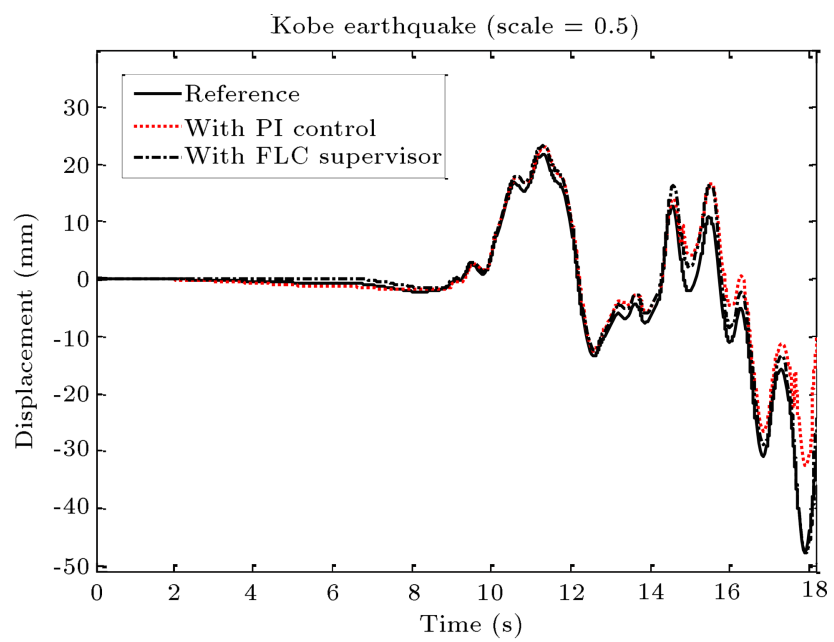

Figure 7. Stage displacement response with $\mathrm{FLC}_{3}$.

In order to measure and compare tracking errors objectively, the RMS criterion (Eq. (2)) may be employed:

$$
\operatorname{Err}_{\mathrm{RMS}}=\sqrt{\frac{\sum_{i=1}^{N}\left(X[i]-X_{\mathrm{ref}}[i]\right)^{2}}{N}}
$$

where $N$ is the number of samples, $X$ is the achieved response, and $X_{\text {ref }}$ is the reference signal.

Figure 8 compares the controllers' performance in displacement tracking based on the mentioned criterion. This figure signifies that the fuzzy supervi-

Table 5. Specification of reference earthquakes.

\begin{tabular}{cc}
\hline Reference earthquake & Specifications \\
\hline Kobe earthquake & Station: Nishi-Akashi \\
& Magnitude: M (6.9); Data source: CUE \\
Chalfant valley earthquake & Station: 54428 Zack Brothers Ranch \\
& Magnitude: Ml (5.9); Data source: CDMG \\
\hline
\end{tabular}




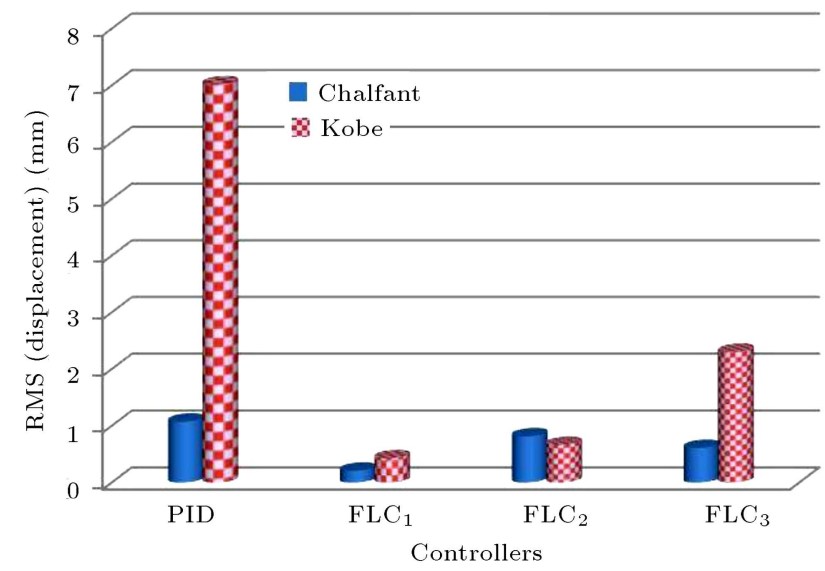

Figure 8. RMS of displacement error with various controllers.

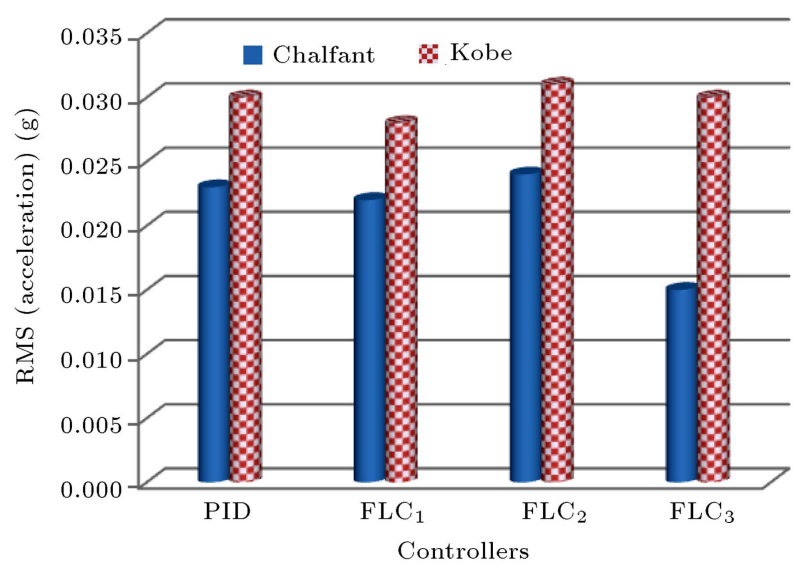

Figure 9. RMS of acceleration error with various controllers.

sory controllers successfully improved the displacement tracking errors for both earthquake types. Moreover, among the fuzzy supervisory controllers, FLC $_{1}$ performed the best.

Figure 9 illustrates the acceleration tracking errors. According to the obtained results, applying $\mathrm{FLC}_{1}$ yields a slight decrease in acceleration tracking error for both earthquakes. In contrast, $\mathrm{FLC}_{2}$ causes higher acceleration tracking error. However, applying $\mathrm{FLC}_{3}$ results in virtually the same level of tracking error for the Kobe earthquake and considerable tracking error for the Chalfant earthquake. Furthermore, although the calculated RMS values for the tracking error are dissimilar to the considered earthquakes using the primary PI controller, according to Figures 8 and 9 , fuzzy supervisory could successfully decrease displacement and acceleration errors substantially. Moreover, after employing the fuzzy-supervisory controller, the displacement and acceleration reduction indicated by RMS criterion are nearly at the same level for both earthquakes, indicating robustness of the supervisory controller in comparison with the PID one.

\section{Conclusion}

A novel fuzzy supervisory controller was designed and implemented for motion control of a seismic shake table in this work. Three different fuzzy supervisory controllers were proposed and implemented in the shake table. The impact of the fuzzy supervisory controller on the shake table's tracking performance was evaluated through testing while emulating the behavior of two predefined earthquakes. It was shown that the fuzzy supervisory controller can drastically improve the displacement tracking performance of the PI controller. Moreover, using the fuzzy supervisory controller attained a slight improvement in acceleration tracking performance.

\section{Acknowledgement}

This research was done under fund No. 90/13736 provided by Arak University.

\section{References}

1. Kima, H., Roschke, P.N. Linc, P. and Loh, C. "Neurofuzzy model of hybrid semi-active base isolation system with FPS bearings and an MR damper", Engineering Structures, 28(7), pp. 947-958 (2006).

2. Barattal, A., Corbi, I., Corbi, O., Barros, R.C. and Bairrao, R. "Shaking table experimental researches aimed at the protection of structures subject to dynamic loading", The Open Construction and Building Technology Journal, 6, pp. 355-360 (2012).

3. Wu, Y.M. and Samali, B. "Shake table testing of a base-isolated model", Engineering Structures, 24(9), pp. 1203-1215 (2002).

4. Lu, X.L. and Jiang, H.J. "Research and practice of response control for tall buildings in mainland China", Procedia Engineering, 14, pp. 73-83 (2011).

5. Severn, R.T. "The development of shaking tables-A historical note", Earthquake Engineering \& Structural Dynamics, 40(2), pp. 195-213 (2011).

6. Yang, X., Hongxing, H. and Junwei, H. "Modeling and controller design of a shaking table in an active structural control system", Mechanical Systems and Signal Processing, 22(8), pp. 1917-1923 (2008).

7. Sinha, P. and Rai, D.C. "Development and performance of single-axis shake table for earthquake simulation", Current Science, 96(12), pp. 1611-1620 (2009).

8. Rakicevic, Z., Garevski, M., Markovski, I. and Naumovski, N. "Upgrading of 5 DOF seismic testing system with the newest real-time three variable digital control system", 5th European Conference on Structural Control, Genoa, Italy (2012).

9. Maoult, A.L., Chaudat, T. and Moutousamy, L. "CEA shaking table control strategy", 5th European Conference on Structural Control, Genoa, Italy (2012). 
10. Seki, K., Iwasaki, M., Kawafuku, M., Hirai, H. and Yasuda, K. "Adaptive compensation for reaction force with frequency variation in shaking table systems", IEEE Transactions on Industrial Electronics, 56(10), pp. 3864-3871 (2009).

11. Yang, X., Hongxing, H. and Junwei, H. "Three state controller design of shaking table in active structural control system", IEEE International Conference on Control and Automation, pp. 88-93 (2007).

12. Lee, D.J., Lim, C.W., Park, Y., Park, Y.S., Eui Kim, H. and Won Park, J. "The tracking control of uniaxial servo-hydraulic shaking table system using time delay control", International Joint Conference, pp. 2932 (2006).

13. Chase, J.G., Hudson, N.H., Lin, J., Elliot, R. and Sim, A. "Nonlinear shake table identification and control for near-field earthquake testing", Journal of Earthquake Engineering, 9(4), pp. 461-482 (2005).

14. Ji, J., Yan, W., Li, Z. and Li, F.F. "The Largescale nine-shaking-tables array system: development, construction", 5th European Conference on Structural Control, Genoa, Italy (2012).

15. Airouche, H., Aknouche, H. Bechtoula, H. "Harmonic signals tracking performance of the CGS servohydraulic shaking table system", 5th European Conference on Structural Control, Genoa, Italy (2012).

16. De Canio, G., Mongelli, M., Roselli, I., Colucci, A. and Di Biagio, F. "An innovative shaking table controller system by 3DVision displacement measures", 5th European Conference on Structural Control, Genoa, Italy (2012).

17. Jantzen, J., Foundations of Fuzzy Control: A Practical Approach, pp. 191-198, John Wiley \& Sons, Chichester, West Sussex, UK (2007).

18. Wang, L.X. "A course in fuzzy systems and control", pp. 249-263, Prentice-Hall International, PTR, Upper Saddle River, NJ (1997).

19. Reigles, D.G. and Symas, M.D. "Supervisory fuzzy control of a base-isolated benchmark building utiliz- ing a neuro-fuzzy model of controllable fluid viscous dampers", Structural Control and Health Monitoring, 13(2-3), pp. 724-747 (2006).

20. Earthquake and Station Details. Retrieved from http: //peer.berkeley.edu.

\section{Biographies}

Mahmoud Hamidizadeh received the MS degree in Mechatronic Engineering from the Arak University, Arak, Iran, in 2013. Since May 2012, he has been with the systems simulation and control laboratory of Arak University, Arak, Iran. His current research interests include motion control and design of mechatronic systems.

Mehdi Soleymani received the $\mathrm{PhD}$ degree in $\mathrm{Me}-$ chanical Engineering from the Iran University of Science and Technology, Tehran, Iran, in 2009, respectively. Since 2009, he has been with the Department of Mechanical Engineering, Arak University, Arak, Iran, where he is currently an Assistant Professor and Director of the systems simulation and control laboratory. His current research interests include structural control and vehicular systems control.

Hasan Moradzadeh received the $\mathrm{PhD}$ degree in Electrical Engineering from the Iran University of Science and Technology in 2010. Since 2010, he has been with the Department of Electrical Engineering, Arak University, Arak, Iran, where he is currently an Assistant Professor. His current research interests include design of electronic and mechatronic systems.

Bahador Ghanbari-S received the MS degree in Mechatronic Engineering, Arak University, Arak, Iran in 2014. Since May 2013, he has been with the systems simulation and control laboratory of Arak University, Arak, Iran. His current research interests include motion control and design of mechatronic systems. 